\title{
Factors Affecting Disease Risk Perception and Self-Management Behaviors among Japanese Long-Term Overseas Volunteers
}

\author{
Kiriko Sasayama $^{*}{ }^{(\mathbb{D},}$, Stuart Gilmour ${ }^{2}$, Erika Ota1 \\ ${ }^{1}$ Department of Global Health Nursing, Graduate School of Nursing Science, St. Luke's International University, Tokyo, Japan \\ ${ }^{2}$ Graduate School of Public Health, St. Luke’s International University, Tokyo, Japan \\ Email: *19dn006@slcn.ac.jp
}

How to cite this paper: Sasayama, K., Gilmour, S. and Ota, E. (2021) Factors Affecting Disease Risk Perception and SelfManagement Behaviors among Japanese Long-Term Overseas Volunteers. Health, 13, 16-30.

https://doi.org/10.4236/health.2021.131002

Received: December 3, 2020

Accepted: January 15, 2021

Published: January 18, 2021

Copyright $\odot 2021$ by author(s) and Scientific Research Publishing Inc. This work is licensed under the Creative Commons Attribution International License (CC BY 4.0).

http://creativecommons.org/licenses/by/4.0/

\begin{abstract}
Introduction: Many overseas volunteers have worked in low and middle-income countries. However traveling abroad and staying in an unfamiliar environment with inadequate medical infrastructure exposes volunteers to a wide range of health risks. The aim of this study was to clarify the relationships among disease knowledge and symptoms, disease risk perception, and self-management skills. Methods: This was a questionnaire survey of 189 Japanese who were preparing to volunteer abroad. A factor analysis was conducted on 13 items (six general risk events and seven major diseases) of risk perception. Correlation analysis was performed between the identified risk perception factors and disease knowledge and symptoms. Risk perception scores by factors from the seven disease items were compared between the Self-management Score (SMS) group and disease knowledge and risk of symptoms group, using T-tests. St. Luke's International University Ethics Committee (19-A092) approved this study. Results: Many participants expected to suffer from digestive diseases $(69.3 \%)$ and dermatitis $(55 \%)$ in the field. On the other hand, few expected high risk of malaria (26.5\%) or dengue fever (36\%). Factor analysis yielded robust factor loadings creating a "Dread" and an "Unknown" factor accounting for $62.2 \%$ of total variance. Strong correlation was not found between SMS and disease risk perception. A weak negative correlation was observed in dengue fever, digestive disorders, and dermatitis ( $\mathrm{r}=-0.20$ to $-0.25, \mathrm{p}<0.001$ ) on the "Unknown" factor. A high SMS score was associated with a lower "Unknown" factor score for malaria, diarrhea, dermatitis, and dental disorders. In addition, higher disease knowledge was significantly associated with higher "Dread" factor score for dental disorders. Conclusions: Self-management skills and disease knowledge will enable higher risk awareness of common diseases and high lethality diseases.
\end{abstract}




\section{Keywords}

Overseas Volunteers, Risk Perception, Self-Management-Skills, Travel-Related Diseases

\section{Introduction}

As globalization has advanced in recent years, many overseas volunteers have worked in low and middle-income countries. Traveling abroad and staying in an unfamiliar environment with inadequate medical infrastructure exposes volunteers to a wide range of health risks [1]. Travelers are usually advised by physicians to receive health information and medical advice prior to their travel in order to deal with possible local diseases [2] [3]. However, self-protection against infectious diseases that can occur during travel is affected by the individual's risk perception, and the severity of disease [4].

Disease risk perception while volunteering abroad is an important factor in volunteer-work risk assessment because it influences the implementation of safety and health measures. For this reason, it is necessary to provide travelers with preventive education in advance so that they can assess and manage the disease risks that may occur at the destination and minimize those risks [5]. However, the relationship between disease knowledge, risk perceptions and self-management skills is unclear.

The aim of this study was to clarify the relationships among disease knowledge and symptoms, disease risk perception, and self-management skills.

\section{Material and Methods}

\subsection{Study Design}

We surveyed Japanese volunteer travelers' disease risk perceptions, used a cognitive map to elucidate and present respondent perceptions, and then developed recommendations for health providers involved in volunteer health education before traveling abroad.

We conducted a questionnaire survey using a purposive sample taken at pre-travel information sessions in two governmental overseas volunteer training centers in Nagano and Fukushima prefectures in Japan. There were two governmental overseas volunteer training centers in Nagano and Fukushima prefectures in Japan. We selected them for purposive sample because they had the largest number of volunteers dispatched to a wide variety of countries. In addition, because they were part of the government, the information about the number of dispatchers and occupations were open to the public. The two centers conducted training for Japanese citizens who would volunteer abroad for 70 days. Both centers conducted trainings three times a year. The training sessions each involved 100 - 200 volunteers. On March 2020 when the survey was conducted, a total of 295 had started training. We distributed a questionnaire to all volunteers 
at both centers who were from 20 to 69 years old. A total of 192 (response rate $65.1 \%$ ) volunteers completed the questionnaire

\subsection{Measurements}

The questionnaire consisted of questions about age, gender, and other characteristics, followed by these questions: 1) seven-items Disease knowledge, 2) 9-items Symptoms prediction after assignment, 3) 10-items Diseases prediction after assignment, 3) 13-items Disease risk perception, 4) 10-items Self-Management Skill.

\subsubsection{Disease Knowledge and Prediction of Symptoms and Diseases after Assignment}

To examine disease knowledge, we selected the seven major diseases that commonly occur during overseas travel, based on previous research: 1) malaria, 2) dengue fever, 3) animal exposure, 4) digestive disorders (such as diarrhea), 5) dermatitis, 6) dental disorders and 7) depression [6] [7] [8] [9] [10]. Volunteers had received lectures from medical professionals on infectious diseases, dental diseases, gynecological diseases, and health care in the developing world months before completing this questionnaire. To measure individual's disease knowledge we asked this question, for each of the seven diseases: "Do you know the health problems caused by this disease?" Response was based on a four-point Likert-type scale $(1=$ do not know at all, $2=$ do not know much, $3=$ know, $4=$ know well). In addition, the symptoms and the major diseases they expected to occur during overseas assignment were asked on a five-point Likert-type scale (1 = never occur, $2=$ rarely, $3=$ sometimes, $4=$ often, $5=$ nearly always $)$.

\subsubsection{Disease Risk Perception Scale}

Research on risk perception includes a theoretical framework that measures subjective risk assessment quantitatively, incorporating both cognitive and emotional aspects of risk perception [11]. This framework evaluates perception of 81 different risks such as genetic engineering, nuclear accidents, alcoholism, bicycle accidents and climate change, and clarified the constituent dimensions into a three-factor structure: "Dread", "Unknown", and "Number of People Exposed". The first factor, "Dread", is lack of control and fear [12] based on considerations of catastrophic potential, fatal consequences, and risks and rewards, with nuclear weapons and nuclear having the highest scores for the features that make up this element. The second factor, "Unknown" defined risks that are unobservable, unknown, new, and perceived as having a delayed onset of harm. The two factors of "Dread" and "Unknown" have been stably extracted in many studies [11]. The measurement of risk perception made by Teigen, Brun, \& Slovic plotted risk events on the two-dimensional space formed by "Dread" and "Unknown", creating a risk cognitive map [13]. To compare past risk perception of general events, we selected the six general risk events (alcohol, smoking, heroin, fireworks, air travel, and diabetes) that previous research examined [13] [14] [15]. Then, we added 1) malaria, 2) dengue fever, 3) animal exposure, 4) digestive 
disorders (such as diarrhea), 5) dermatitis, 6) dental disorders and 7) depression, the seven disease risks.

Teigen et al. identified nine standard dimensions of risk that contributed to high factor loadings [13]. We asked subjects to judge each general event and diseases on each of nine dimensions of risk scales, measured on a seven-point Likert-type scale. These nine dimensions of risk were: 1) voluntariness of risk (1 = voluntary, 7 = involuntary $), 2)$ immediacy of effect $(1=$ immediate; $7=$ delayed), 3) knowledge about risk by exposed person ( $1=$ known to exposed; $7=$ not known to exposed), 4) knowledge about risk by scientists ( $1=$ known to science, 7 = not known to science), 5) control over risk $(1=$ not controllable; $7=$ controllable, 6) newness $(1=$ new; $7=$ old $), 7)$ catastrophic potential $(1=$ chronic, 7 = catastrophic $), 8)$ dreadfulness $(1=$ common; $7=$ dread $), 9)$ severity of consequences $(1=$ certain not fatal; $7=$ certainly fatal $)$.

\subsubsection{Self-Management Skill Scale}

A reliable and valid 10-item Self-Management Skill scale (SMS) was used to measure self-management skills [16] [17]. These used a four-point Likert-type scale $(1=$ strongly agree, $2=$ agree, $3=$ disagree, $4=$ strongly disagree $)$, which were summed to produce a final score between 10 and 40 .

\subsection{Statistical Analysis}

Factor analysis was conducted on the risk perception scale of 13 items using the maximum likelihood method and varimax rotation. Two factors were adopted. Correlation analysis was performed between the identified factors and disease knowledge, SMS score and seven items of disease risk perception. SMS, disease knowledge and risk of symptoms were divided by average score into high and low groups. Disease risk perception scores by factors from the seven diseases were compared between the low/high SMS group and low/high knowledge of health risk groups using T-tests. A risk cognition map was created consisting of coordinates in a two-factor space created by the Dread factor and Unknown factor, which are components of disease risk perception. IBM SPSS Statistics 26 was used for the analysis. The significance level was set at $\mathrm{p}<0.05$.

\subsection{Ethical Considerations}

After obtaining consent from the participating volunteer agencies, completion of the questionnaire was understood as consent. Anonymity and protection of data was assured. The research collaborators who were described in the research protocol and who worked as nurses and staff caring for volunteers in the training center collected the questionnaires, which were returned to the researcher. St. Luke's International University ethics committee 2019 (19-A092) approved this study.

\section{Results}

Of the 192 respondents to the questionnaires, 189 were valid responses (three 
questionnaires were incomplete) with 88 men (46.6\%), 97 women (51.3\%) and four unknown sex (2.1\%) (Table 1). The average age of respondents was $34.2 \pm$ 12.5 years old, with a mode of 20 years old. Volunteers were assigned to Latin America (35.4\%), Africa (25.4\%), Asia (16.9\%), Oceania (11.6\%), the Middle East (2.1\%), and unknown (8.5\%). Many of the planned volunteer activities were human resource tasks related to local educational activities, followed by health, medical care and social work (19\%). Health care professionals were $21 \%$ of participants.

\subsection{Disease Knowledge and Prediction of Diseases and Symptoms after Assignment}

Disease knowledge as analyzed after converting Likert scale results into binary categories, and is shown in Table 2. More than half of participants knew about these diseases. Many participants expected to suffer from digestive diseases (69.3\%) and dermatitis (55\%) in the field. On the other hand, few people expected to experience tropical infections such as malaria (25.9\%) or dengue fever (35.4\%). Diarrhea (79.9\%) was the most common symptom expected to occur, followed by abdominal pain (76.2\%), cold symptoms (68.3\%), skin irritation (64.6\%), and moodiness (59.3\%). Participants were least likely to predict the onset of toothache $(37 \%)$.

\subsection{Structure of Disease Risk Perception Scale}

A correlation matrix of responses on nine dimensions of risk was used for factor analysis. A factor analysis was performed using maximum likelihood with varimax rotation assuming no intercorrelations between components. Seven of the nine risk dimensions had high loadings yielding Factor 1 and Factor 2. The seven risk dimensions accounted for $62.2 \%$ of total variance and had acceptable factor loadings of 0.41 or more (Table 3). We named the factors based on Slovic's study [12]. Factor 1 included severity of consequences, dreadfulness, catastrophic potential, and immediacy of effect and was named Dread. The Cronbach's alpha coefficient was 0.81 for the four items. Factors 2 included knowledge about risks by exposed person, knowledge about risk by scientist, and control over risk, which was named Unknown. Cronbach's alpha was 0.77 for the three items.

\subsection{Correlation with Disease Risk Perception}

To examine the relationship between the SMS and the two factors of risk perception (Dread and Unknown) we calculated the Pearson's correlation coefficient between them. Strong correlation was not found between SMS and disease risk perception (Table 4). However, there were correlations between Dread factor score and disease knowledge for digestive disease $(r=0.24, \mathrm{p}<0.001)$ (Table 5). A weak negative correlation was observed in dengue fever, digestive disorders, and dermatitis $(\mathrm{r}=-0.20$ to $-0.25, \mathrm{p}<0.001)$ on the Unknown factor. 
Table 1. Demographic characteristics of participants.

\begin{tabular}{|c|c|c|c|}
\hline Characteristics & \multicolumn{3}{|c|}{ Number of participants (/189) } \\
\hline Male & 88 & 46.6 & $\%$ \\
\hline Female & 97 & 51.3 & $\%$ \\
\hline unknown & 4 & 2.1 & $\%$ \\
\hline \multicolumn{4}{|l|}{ Age group } \\
\hline $20-29$ & 96 & 50.8 & $\%$ \\
\hline $30-39$ & 43 & 22.8 & $\%$ \\
\hline $40-49$ & 11 & 5.8 & $\%$ \\
\hline $50-59$ & 12 & 6.3 & $\%$ \\
\hline over 60 & 15 & 7.9 & $\%$ \\
\hline unknown & 12 & 6.3 & $\%$ \\
\hline \multicolumn{4}{|l|}{ Region of assignment ${ }^{*}$} \\
\hline South and Central America & 67 & 35.4 & $\%$ \\
\hline Africa & 48 & 25.4 & $\%$ \\
\hline Asia & 32 & 16.9 & $\%$ \\
\hline Oceania & 22 & 11.6 & $\%$ \\
\hline Middle east & 4 & 2.1 & $\%$ \\
\hline unknown & 16 & 8.5 & $\%$ \\
\hline \multicolumn{4}{|l|}{ Occupation } \\
\hline Human resources & 62 & 32.8 & $\%$ \\
\hline Health and Medical Care & 37 & 19.6 & $\%$ \\
\hline Planning administration & 28 & 14.8 & $\%$ \\
\hline Agriculture, forestry and fisheries & 17 & 9 & $\%$ \\
\hline Commerce and tourism & 11 & 5.8 & $\%$ \\
\hline Mining industry & 9 & 4.8 & $\%$ \\
\hline Social welfare & 6 & 3.2 & $\%$ \\
\hline Public and public interest & 2 & 1.1 & $\%$ \\
\hline Unknown & 17 & 9 & $\%$ \\
\hline \multicolumn{4}{|l|}{ Educational Background } \\
\hline Bachelor's & 131 & 69.3 & $\%$ \\
\hline Master's & 22 & 11.6 & $\%$ \\
\hline College or Community College & 19 & 10.1 & $\%$ \\
\hline Others & 9 & 4.8 & $\%$ \\
\hline Unknown & 8 & 4.2 & $\%$ \\
\hline \multicolumn{4}{|l|}{ Experience as a medical professional } \\
\hline Yes & 40 & 21.2 & $\%$ \\
\hline No & 142 & 75.1 & $\%$ \\
\hline Unknown & 7 & 3.7 & $\%$ \\
\hline
\end{tabular}

* South and Central America: Argentina, Dominican, Guatemala, Belize, Bolivia, Chile, Colombia, Costa Rica, Ecuador, El Salvador, Honduras, Jamaica, Mexico, Nicaragua, Panama, Paraguay, Peru, Republic, Saint Lucia, Saint Vincent. Africa: Benin, Botswana, Cameroon, Djibouti, eSwatini, Ethiopia, Gabon, Ghana, Kenya, Lesotho, Madagascar, Malawi, Mozambique, Namibia, Rwanda, Senegal, South Africa, Tanzania, Uganda, Zambia, Zimbabwe; Asia: Bhutan, Cambodia, China, India, Indonesia, Kyrgyzstan, Malaysia, Maldives, Mongolia, Myanmar, Nepal, Philippines, Singapore, Thailand, Timor-Leste, Uzbekistan, Viet Nam, Lao; Oceania: Fiji, Kiribati, Marshall, Micronesia, Palau, Papua New Guinea, Samoa, Solomon, Tonga, Vanuatu; Middle east and Europe: Egypt, Jordan, Morocco, Tunisia, Serbia. 
Table 2. Knowledge of Disease, symptoms and diseases to be expected after the assignment.

\begin{tabular}{|c|c|c|c|c|c|c|c|}
\hline \multirow{2}{*}{ Question } & \multicolumn{3}{|c|}{ Yes } & \multicolumn{2}{|c|}{ No } & \multicolumn{2}{|c|}{ no answer } \\
\hline & N (189) & $\mathrm{n}$ & $\%$ & $\mathrm{n}$ & $\%$ & $\mathrm{n}$ & $\%$ \\
\hline \multicolumn{8}{|c|}{ Do you know the health problems caused by this disease? } \\
\hline Dental disorders & & 123 & $(65.1)$ & 65 & $(34.4)$ & 1 & $(0.5)$ \\
\hline Animal exposure & & 123 & $(65.1)$ & 66 & $(34.9)$ & & \\
\hline Digestive diseases & & 118 & $(62.4)$ & 70 & (37) & 1 & $(0.5)$ \\
\hline Depression & & 116 & $(61.4)$ & 72 & $(38.1)$ & 1 & $(0.5)$ \\
\hline Malaria & & 113 & $(59.8)$ & 76 & $(40.2)$ & & \\
\hline Dengue fever & & 108 & $(57.1)$ & 81 & $(42.9)$ & & \\
\hline Dermatitis & & 106 & $(56.1)$ & 83 & $(43.9)$ & & \\
\hline \multicolumn{8}{|c|}{ Do you expect this disease to occur during overseas assignment? } \\
\hline Digestive diseases & & 131 & $(69.3)$ & 56 & $(29.6)$ & 2 & $(1.1)$ \\
\hline Dermatitis & & 104 & (55) & 84 & $(44.4)$ & 1 & $(0.5)$ \\
\hline Dental disorders & & 85 & $(45)$ & 103 & $(54.5)$ & 1 & $(0.5)$ \\
\hline Animal exposure & & 73 & $(38.6)$ & 114 & $(60.3)$ & 2 & $(1.1)$ \\
\hline Dengue fever & & 67 & $(35.4)$ & 121 & (64) & 1 & $(0.5)$ \\
\hline Depression & & 60 & $(31.7)$ & 125 & $(66.1)$ & 4 & $(2.1)$ \\
\hline Malaria & & 49 & $(25.9)$ & 139 & $(73.5)$ & 1 & $(0.5)$ \\
\hline \multicolumn{8}{|c|}{ Do you expect this symptom to occur during overseas assignment? } \\
\hline Diarrhea & & 151 & $(79.9)$ & 38 & $(20.1)$ & & \\
\hline Abdominal pain & & 144 & $(76.2)$ & 45 & $(23.8)$ & & \\
\hline Cold symptoms & & 129 & $(68.3)$ & 60 & $(31.7)$ & & \\
\hline Skin irritation & & 122 & $(64.6)$ & 66 & $(34.9)$ & & \\
\hline Moodiness & & 112 & $(59.3)$ & 77 & (40) & & \\
\hline Fever & & 110 & $(58.2)$ & 79 & $(41.8)$ & & \\
\hline Insomnia & & 86 & $(45.5)$ & 102 & (54) & 1 & $(0.5)$ \\
\hline Toothache & & 70 & (37) & 119 & (63) & & \\
\hline
\end{tabular}

Table 3. Factor loadings of dimensions of risk.

\begin{tabular}{|c|c|c|c|c|c|}
\hline & & \multicolumn{4}{|c|}{ Factor loading } \\
\hline & & Dimensions & I & II & Commonality \\
\hline \multirow{4}{*}{ I } & \multirow{4}{*}{$\begin{array}{l}\text { Dread } \\
\text { factor }\end{array}$} & Severity of consequences & 0.99 & 0.01 & 0.98 \\
\hline & & Dreadfulness & 0.96 & 0.00 & 0.93 \\
\hline & & Catastrophic potential & 0.50 & 0.26 & 0.31 \\
\hline & & Immediacy of effect & 0.41 & 0.40 & 0.32 \\
\hline \multirow{6}{*}{ II } & & Knowledge about risk by exposed person & 0.06 & 0.87 & 0.76 \\
\hline & $\begin{array}{l}\text { Unknown } \\
\text { factor }\end{array}$ & Knowledge about risk by scientist & -0.04 & 0.87 & 0.75 \\
\hline & & Risk control & 0.25 & 0.49 & 0.31 \\
\hline & & $\alpha$ coefficient & 0.81 & 0.77 & \\
\hline & & Factor contribution & 2.39 & 1.97 & \\
\hline & & Accounting (\%) & 34.1 & 62.2 & \\
\hline
\end{tabular}


Table 4. Pearson's correlation coefficient of two factors and Self-Management Skill score.

\begin{tabular}{ccc}
\hline Disease & Dread factor and SMS score & Unknown factor and SMS score \\
\hline Malaria & -0.01 & -0.13 \\
Dengue fever & $-0.03^{*}$ & -0.08 \\
Animal exposure & 0.07 & -0.01 \\
Digestive diseases & 0.05 & $-0.18^{\star}$ \\
dermatitis & 0.02 & $-0.18^{*}$ \\
Dental disorders & 0.12 & -0.11 \\
Depression & -0.03 & -0.14 \\
\hline
\end{tabular}

* Correlation coefficient is significant at the $5 \%$ level (two-sided).

Table 5. Spearman's Correlation coefficient of two factors and Knowledge of Disease.

\begin{tabular}{ccc}
\hline Disease & Dread factor and knowledge score & Unknown factor and knowledge score \\
\hline Malaria & 0.08 & -0.13 \\
Dengue fever & $0.14^{*}$ & $-0.20^{* *}$ \\
Animal exposure & $0.15^{*}$ & -0.08 \\
Digestive disease & $0.24^{* *}$ & $-0.25^{* *}$ \\
dermatitis & 0.12 & $-0.20^{* *}$ \\
Dental disorders & $0.16^{*}$ & -0.10 \\
Depression & 0.14 & -0.12
\end{tabular}

* Correlation coefficient is significant at the $5 \%$ level (two-sided), ${ }^{* *}$ Correlation coefficient is significant at $1 \%$ level (two-sided).

\subsection{Comparison of Risk Dimensions for Each of the Seven Diseases by SMS Score and Disease Knowledge Score}

To compare SMS, disease knowledge and the risk dimensions, an SMS average score less than 20.9 was defined as the low self-management skill group (SMS low group), and a score of 20.9 or higher as the high self-management skill group (SMS high group) (Table 6). The Dread scores were not significantly different between the SMS low and high groups for the seven diseases. The Unknown scores for malaria ( $3.08 \pm 0.96$ vs. $2.73 \pm 1.04$ ), digestive disorders ( $3.14 \pm$ 0.93 vs. $2.78 \pm 1.04$ ), dermatitis ( $3.62 \pm 0.84$ vs. $3.17 \pm 1.15$ ), and dental disorders $(2.93 \pm 0.99$ vs. $2.62 \pm 0.89)$ were higher in the low SMS group than in the high SMS group. The Unknown score for total diseases was significantly higher in the low SMS group than the high SMS group.

A disease knowledge score less than 19.0 was defined as low knowledge level, and a score of 19.0 or higher as the high knowledge level group. The Dread and Unknown scores for each of the seven diseases were compared by disease knowledge group (Table 7). The Dread score was significantly higher for dental disorders $(3.93 \pm 1.38$ vs. $4.33 \pm 0.91)$ in the high disease knowledge group. The Unknown factor score was significantly lower in the high disease knowledge group with digestive disease $(3.14 \pm 1.14$ vs. $2.77 \pm 1.02)$. The Dread score for 
total diseases was significantly higher in the high knowledge than the low disease knowledge group ( $4.21 \pm 1.01$ vs. $4.57 \pm 0.82)$.

Table 6. Low/high SMS average by Dread and Unknown factor scores and diseases.

\begin{tabular}{|c|c|c|c|c|c|c|}
\hline \multirow{2}{*}{ Disease } & \multirow{2}{*}{ Factor } & \multicolumn{2}{|c|}{ Low SMS $(\mathrm{n}=72)$} & \multicolumn{2}{|c|}{ High SMS $(\mathrm{n}=103)$} & \multirow{2}{*}{$P$ value } \\
\hline & & Average score & SD & Average score & $\mathrm{SD}$ & \\
\hline \multirow{2}{*}{ Malaria } & Dread & 4.73 & 1.01 & 4.80 & 1.24 & n.s \\
\hline & Unknown & 3.08 & 0.96 & 2.73 & 1.04 & 0.03 \\
\hline \multirow{2}{*}{ Dengue fever } & Dread & 4.66 & 1.00 & 4.61 & 1.19 & n.s \\
\hline & Unknown & 3.26 & 1.08 & 2.97 & 1.07 & n.s \\
\hline \multirow{2}{*}{ Animal exposure } & Dread score & 4.34 & 1.05 & 4.61 & 1.17 & n.s \\
\hline & Unknown & 2.91 & 1.01 & 2.78 & 1.07 & n.s \\
\hline \multirow{2}{*}{ Digestive diseases } & Dread score & 4.25 & 1.04 & 4.42 & 1.2 & n.s \\
\hline & Unknown & 3.14 & 0.93 & 2.78 & 1.04 & 0.02 \\
\hline \multirow{2}{*}{ Dermatitis } & Dread & 4.27 & 0.84 & 4.27 & 1.17 & n.s \\
\hline & Unknown & 3.62 & 0.84 & 3.17 & 1.15 & 0.01 \\
\hline \multirow{2}{*}{ Dental disorders } & Dread & 4.16 & 0.99 & 4.38 & 0.86 & n.s \\
\hline & Unknown & 2.93 & 0.99 & 2.62 & 0.89 & 0.04 \\
\hline \multirow{2}{*}{ Depression } & Dread & 4.67 & 1.27 & 4.59 & 0.94 & n.s \\
\hline & Unknown & $\underline{3.68}$ & $\underline{1.09}$ & $\underline{3.42}$ & $\underline{0.99}$ & $\underline{\mathrm{n} . \mathrm{s}}$ \\
\hline \multirow{2}{*}{ Total } & Dread & 4.44 & 0.75 & 4.5 & 0.84 & n.s \\
\hline & Unknown & 3.23 & 0.75 & 2.9 & 0.81 & 0.01 \\
\hline
\end{tabular}

${ }^{*}$ n.s. $=$ not significant, $\mathrm{SD}=$ standard deviation.

Table 7. Knowledge Level average by Dread and Unknown factor scores and diseases.

\begin{tabular}{|c|c|c|c|c|c|c|}
\hline \multirow{3}{*}{ Disease } & \multirow{3}{*}{ Factor } & \multirow{2}{*}{\multicolumn{2}{|c|}{$\begin{array}{l}\text { Low } \\
\text { knowledge level }(n=78)\end{array}$}} & \multirow{2}{*}{\multicolumn{2}{|c|}{$\begin{array}{l}\text { High } \\
\text { knowledge level }(\mathrm{n}=111)\end{array}$}} & \multirow{3}{*}{$\mathrm{p}$ value } \\
\hline & & & & & & \\
\hline & & Average score & $\mathrm{SD}$ & Average score & $\mathrm{SD}$ & \\
\hline \multirow{2}{*}{ Malaria } & Dread & 4.59 & 1.26 & 4.88 & 1.14 & $\mathrm{n}, \mathrm{s}$ \\
\hline & Unknown & 2.97 & 1.17 & 2.77 & 0.91 & $\mathrm{n}, \mathrm{s}$ \\
\hline \multirow{2}{*}{ Dengue fever } & Dread & 4.38 & 1.26 & 4.73 & 1.11 & n.s \\
\hline & Unknown & 3.27 & 1.32 & 2.93 & 0.93 & 0.04 \\
\hline \multirow{2}{*}{ Animal exposure } & Dread & 4.25 & 1.33 & 4.58 & 1.1 & $\mathrm{n}, \mathrm{s}$ \\
\hline & Unknown & 2.86 & 1.19 & 2.74 & 0.98 & $\mathrm{n}, \mathrm{s}$ \\
\hline \multirow{2}{*}{ Digestive diseases } & Dread & 3.99 & 1.24 & 4.51 & 1.17 & $\mathrm{n}, \mathrm{s}$ \\
\hline & Unknown & 3.14 & 1.14 & 2.77 & 1.02 & 0.02 \\
\hline \multirow{2}{*}{ Dermatitis } & Dread & 4.04 & 1.22 & 4.34 & 1.03 & $\mathrm{n}, \mathrm{s}$ \\
\hline & Unknown & 3.44 & 1.25 & 3.29 & 1.00 & $\mathrm{n}, \mathrm{s}$ \\
\hline \multirow{2}{*}{ Dental disorders } & Dread & 3.93 & 1.38 & 4.33 & 0.91 & 0.02 \\
\hline & Unknown & 2.68 & 1.18 & 2.68 & 0.91 & $\mathrm{n}, \mathrm{s}$ \\
\hline \multirow{2}{*}{ Depression } & Dread & 4.31 & 1.54 & 4.64 & 1.1 & $\mathrm{n}, \mathrm{s}$ \\
\hline & Unknown & 3.53 & 1.34 & 3.35 & 1.04 & $\mathrm{n}, \mathrm{s}$ \\
\hline \multirow{2}{*}{ Total } & Dread & 4.21 & 1.01 & 4.57 & 0.82 & 0.008 \\
\hline & Unknown & 3.12 & 0.98 & 2.93 & 0.73 & n.s \\
\hline
\end{tabular}

${ }^{*}$ n.s. $=$ not significant, $\mathrm{SD}=$ standard deviation. 


\subsection{Factor Space Diagram as a Risk Cognitive Map of Dread and Unknown Factors}

To conceptualize the risk perception of the 13 risk items, we calculated the average Dread score and Unknown score, and made a factor space diagram as a risk cognitive map with Dread factor as the $\mathrm{x}$-axis and Unknown factor as the $\mathrm{y}$-axis (Figure 1).

We developed a cognitive map to understand and predict both expectations as well as responses to certain high-risk events [12]. Dread items are located horizontally left $($ lower $=1$ ) to right (higher $=7$ ), and Unknown items are located vertically. The risk perceptions of the 13 risk events fell into in the 4th quadrant (lower right); with air travel having the highest Dread level, and dental disorders the lowest. This pattern was repeated from the disease knowledge scores.

\section{Discussion}

This study is the first study in Japanese volunteers that investigated the relationship among disease knowledge, risk perception and self-management skills expected after the assignment using the risk perception scale.

Only one-fifth of volunteers were involved in the health care and medical profession, but all volunteers had taken health lecture on infectious diseases, health care and dental diseases during the training before taking this survey. However not all of the participants knew about the seven major diseases that commonly occur during overseas travel. About $40 \%$ of volunteers knew about more dangerous diseases such as malaria and dengue fever. Knowledge of these diseases was probably lower than other diseases because not all volunteers planned to go the countries affected by malaria, so they may not have learned about this disease. However although $89.4 \%$ of the participants would work in the countries affected by dengue fever, $42.9 \%$ of participants did not understand the risk posed by this disease. The global incidence of dengue fever has increased dramatically over recent decades as a major cause of serious illness in some Asian and Latin American countries (24). Acquisition of knowledge about dengue fever is necessary in future health education of volunteers.

We found two robust factors in factor analysis: Dread is composed of four items of severity of consequences, dreadfulness, catastrophic potential, and immediacy of effect (Cronbach's $\alpha$ coefficient is 0.81 ); Factor 2, termed Unknown, was knowledge about risks by exposed people, knowledge about risk by scientists, and control over risk (Cronbach's $\alpha$ coefficient $=0.77$ ). Since the risk characteristics used in this study were different from previous studies [14] [15] [18] [19], the results were also slightly different. However, the concepts indicating the respective risks were contained within similar constituent factors. The factor analysis explained $62.2 \%$ of the variance, which was slightly higher than that in those previous studies, and it could explain the overall risk perception to some extent, and indicates the scale has reasonable validity [14] [15] [19].

There was no strong correlation between disease knowledge and disease risk perception or self-management skills. Disease knowledge and Unknown factor 


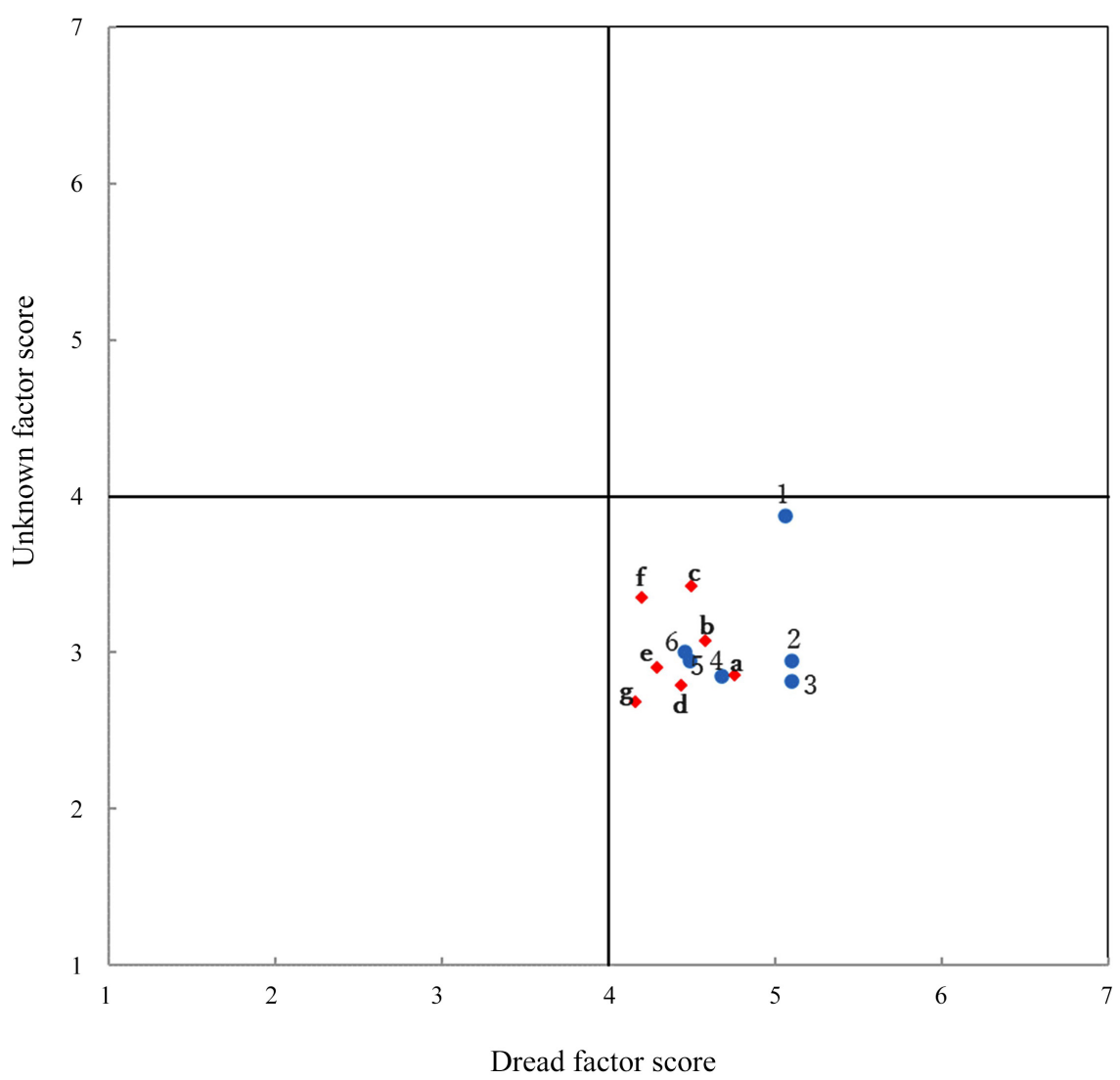

Figure 1. Factor space diagram created a cognitive risk map by plotting 13 risk items by the two factors, Dread and Unknown factors. $\diamond$ Travel risk items (7 items): a = malaria; $\mathrm{b}=$ dengue fever; $\mathrm{c}=$ depression; $\mathrm{d}=$ animal exposure; $\mathrm{e}=$ digestive diseases; $\mathrm{f}=$ dermatitis; $\mathrm{g}=$ dental disorders; $\mathrm{O}$ General items (6 items): 1 = air travel; 2 = smoking; 3 = fireworks; 4 = heroin; 5 = alcohol; 6 = diabetes. Horizontal axis figures indicate low Dread $=1$ and high Dread $=7$; Vertical axis figures indicate $1=$ low Unknown and high Unknown $=7$.

scores were slightly negatively correlated with three disease categories: dengue fever, digestive disease and dermatitis. In other words, the more participants thought they did not know about these diseases, the stronger the image of the unknown.

A high SMS score was associated with lower Unknown score of malaria, digestive diseases, dermatitis, and dental disorders. For the mean value of all diseases, higher SMS scores were associated with lower Unknown scores. Several studies reported that people with higher self-management skills were less likely to drop out of smoking cessation campaigns, and diabetics with higher selfmanagement skills were able to manage their diet and exercise [17] [20]. People with high self-management skills are more aware of common diseases in Japan, such as diarrhea, dermatitis, and dental disorders, in order to focus on prevention before diseases occur. In addition, malaria is a dangerous and well-known disease that people with high self-management skills are likely to have researched before departure. 
Disease knowledge and self-management skill affect disease-related concerns and dread, coping with anxiety, constructive attitudes and approaches, as well as coping with disease-related negative emotions [21]. We thought that higher disease knowledge and higher self-management skills would be associated with a lower Dread score. However, with the exception of dental disease, there was no difference in Dread score regardless of disease knowledge or self-management skills. The respondents in this study did not expect to develop dental disease in their assignment countries, but the group with high disease knowledge could understand the risks and difficulties of this condition. Actually, dental problems are common in overseas volunteers, because caries tends to occur when living in areas without potable water or hygienic conditions in developing countries [22] [23]. It is reported that pre-travel dental treatment is important to avoid the risk of local dental treatment in British volunteers [22].

A factor space diagram created a cognitive risk map by plotting 13 risk items in quadrants or factor spaces defined by the two factors, Dread and Unknown. In this cognitive risk map, smoking, heroin use, alcohol, fireworks, air travel, and diabetes were all in the high Dread and low Unknown quadrants. Compared to another study of Japanese people by Mihashi, alcohol, smoking, drug use, and diabetes would be placed in the lower two quadrants (low Dread and low Unknown factor spaces) [14]. Since this study found that the respondents were going to developing countries, the Dread scores were higher for all items. Because the participants were people who were in training before going to volunteer in developing countries, importantly risk perception varies by race [24] and also depends on when it was measured and the characteristics of the respondents.

Risk cognitive maps in which the risk located is in the upper left of quadrant four (high Dread factor and low Unknown factor), suggests that the prediction of risk status is appropriate [14] [15]. In our results, all the diseases were positioned in the lower left of quadrant four, which suggests volunteers were afraid of the disease and were not underestimating the risks. However, comparing the risks of each one, there is a cognitive gap in the perception that the risk of malaria and dengue fever were lower than the risk from smoking. Although $37 \%$ of all responders would travel to Africa and Oceania where malaria is a higher risk the dread score of malaria was lower than that of smoking and fireworks. It is possible they would perceive malaria as preventable by taking chemoprophylaxis and using personal preventive means even though neither are $100 \%$ effective [25].

This study found that the perception of risk from a disease differs depending on self-management skills and disease knowledge. Risk perception for diseases with high lethality such as malaria and dengue fever were different compared to the lower lethality diseases such as dermatitis d dental disease. People tend to underestimate the probability of risks that have a relatively high probability of occurrence and to over-estimate a high risk with a small probability that rarely occurs [18]. However, people with self-management skills and disease know- 
ledge will have higher risk awareness of common diseases including high lethality diseases. Therefore, it is important to give not only preventive knowledge but also education in self-management skills before traveling. Takahashi et al., who developed the SMS scale, stated that self-management skills include emotional skills, such as encouraging oneself by manipulating thoughts, and non-emotional skills, such as facilitating the execution of actions through strategic thinking. This scale has items consisting of information gathering for appropriate decision making, planning for achieving objectives, and self-evaluation. Considering this scale, it is necessary to acquire the ability to be able to recognize by oneself how to act on disease knowledge in actual overseas situations. The next research that needs to be done will be done in health behavior research to investigate how volunteer can predict disease and how volunteer can take action.

This study had several limitations. First, we cannot generalize our findings from our volunteer target population. Second, the questionnaire may have introduced responder bias, as certain types of volunteers may have been more likely to complete the survey compared to others. The scale used in this study was for measurement of general risk and not for the risk of disease during travel across activities. It may be not as valid and reliable for risk of disease. However, this is the first study to measure the disease perception, the disease knowledge, and the self-management skills for Japanese overseas volunteers before dispatch. Furthermore, more research is necessary to verify the reliability and validity of the risk perception scale in order to support their health.

\section{Conclusion}

Higher self-management skills were associated with lower "Unknown" factor of risk perception, while higher disease knowledge was associated with higher "Dread" factor of risk perception. Self-management skills and disease knowledge will enable higher risk awareness of common diseases and high lethality diseases. Therefore, it is important to give not only preventive knowledge but also education on self-management skills.

\section{Acknowledgements}

We would like to thank the participants and staff at Japanese International Cooperation Agency Komagane Training Center and Nihonmatsu Training Center. Sarah E. Porter PhD, MPH, MS, RN provided editorial assistance.

\section{Conflicts of Interest}

The authors declare no conflicts of interest regarding the publication of this paper.

\section{References}

[1] Küpper, T., Rieke, B., Neppach, K., Morrison, A. and Martin, J. (2013) Health Hazards and Medical Treatment of Volunteers Aged 18-30 Years Working in Interna- 
tional Social Projects of Non-Governmental Organizations (NGO). Travel Medicine and Infectious Disease, 12, 385-395. https://doi.org/10.1016/j.tmaid.2013.11.004

[2] Heywood, A.E., Watkins, R.E., Iamsirithaworn, S., Nilvarangkul, K. and MacIntyre, C.R. (2012) A Cross-Sectional Study of Pre-Travel Health-Seeking Practices among Travelers Departing Sydney and Bangkok Airports. BMC Public Health, 12, 321. https://doi.org/10.1186/1471-2458-12-321

[3] World Health Organization (2020) Travel Precautions. https://www.who.int/news-room/q-a-detail/travel-precautions

[4] Sridhar, S., Regner, I., Brouqui, P. and Gautret, P. (2016) Methodologies for Measuring Travelers' Risk Perception of Infectious Diseases: A Systematic Review. Travel Medicine and Infectious Disease, 14, 360-372. https://doi.org/10.1016/j.tmaid.2016.05.012

[5] Stadtländer, C.T.K.H. (2016) CDC Health Information for International Travel 2016. https://doi.org/10.4269/ajtmh.16-0627

[6] Hadano, Y., Shirano, M. and Goto, T. (2016) Travel-Related Illness at a Tertiary Care Hospital in Osaka, Japan. International Journal of General Medicine, 9, 355 359. https://doi.org/10.2147/IJGM.S117513

[7] Hamada, A. (2016) Travel Medicine and Infectious Diseases for Travelers. Japanese Society of Internal Medicine, 105, 1455-1462.

https://doi.org/10.2169/naika.105.1455

[8] Hirata, K., Ogawa, T., Fujikura, H., Ogawa, Y., Hirai, N., Nakagawa-Onishi, T., Konishi, M., et al. (2018) Characteristics of Health Problems in Returned Overseas Travelers at a Tertiary Teaching Hospital in a Suburban Area in Japan. Journal of Infection and Chemotherapy, 24, 682-685. https://doi.org/10.1016/j.jiac.2018.02.003

[9] Mizuno, Y. and Kudo, K. (2009) Travel-Related Health Problems in Japanese Travelers. Travel Medicine and Infectious Disease, 7, 296-300.

https://doi.org/10.1016/j.tmaid.2009.03.002

[10] Yoshimura, Y., Miyata, N., Miyajima, M., Sakamoto, Y., Amano, Y. and Tachikawa, N. (2016) Diseases Affecting Patients Returning from Abroad: Experience of a Travel Clinic in Japan from 2004 to 2014. Journal of Infection and Chemotherapy, 23, 35-39. https://doi.org/10.1016/j.jiac.2016.09.005

[11] Slovic, P. (2000) The Perception of Risk. Earthscan Pub., London.

[12] Slovic, P. (1987) Perception of Risk. Science, 236, 280-285. https://doi.org/10.1126/science.3563507

[13] Teigen, K.H., Brun, W. and Slovic, P. (1988) Societal Risks as Seen by a Norwegian Public. Journal of Behavioral Decision Making, 1, 111-130. https://doi.org/10.1002/bdm.3960010205

[14] Mihashi, M. (2004) The Risk Cognition of Infectious Disease and the Analysis for Risk Control on Space by Two Factors. Journal of Japan Society of Disaster Nursing, 6, 7-20.

[15] Mihashi, M. (2004) Possibility of Trial for Risk Cognition Map of Infectious Disease and Extraction of Necessary Information Extraction of Information about "Risk Image" and "Influence Factors of Risk Cognition". Journal of Japan Academy of Nursing Science, 24, 60-71. https://doi.org/10.5630/jans1981.24.3 60

[16] Takahashi, H., Nakamura, M., Kinoshita, T. and Masui, S. (2000) Development and Validation of a Self-Management Skill Scale. Japanese Journal of Public Health, 47, 907-914. https://www.jsph.jp/docs/magazine/2000/11/47 11 0907.pdf

[17] Takahashi, H., Takehana, Y. and Sami, Y. (2004) Difference of Self-Management 
Skill among Various Age Groups. Japanese Journal of Health Education and Promotion, 12, 80-87.

[18] Kleinhesselink, R.R. and Rosa, E.A. (1991) Cognitive Representation of Risk Perceptions: A Comparison of Japan and the United States. Journal of Cross-Cultural Psychology, 22, 11-28. https://doi.org/10.1177/0022022191221004

[19] Mihashi, M., Xin, Y., Otsubo, Y. and Ishitaka, T. (2007) Relationship between Understanding of Infectious Disease and Risk Cognition through the Experience of the SARS Outbreak. Journal of the Kurume Medical Association, 70, 78-86.

[20] Takehana, Y. and Takahashi, H. (2002) Relationship between Self-Management Behavior and Cognitive Skill in Type 2 Diabetes Mellitus Patients. Japanese Society of Public Health, 49, 1159-1168.

[21] Berding, A., Witte, C., Gottschald, M., Kaltz, B., Weiland, R., Gerlich, C., Faller, H., et al. (2016) Beneficial Effects of Education on Emotional Distress, Self-Management, and Coping in Patients with Inflammatory Bowel Disease: A Prospective Randomized Controlled Study. Inflammatory Intestinal Diseases, 1, 182-190. https://doi.org/10.1159/000452989

[22] Bhatta, P., Simkhada, P., van Teijlingen, E. and Maybin, S. (2009) A Questionnaire Study of Voluntary Service Overseas (VSO) Volunteers: Health Risk and Problems Encountered. Journal of Travel Medicine, 16, 332-337. https://doi.org/10.1111/j.1708-8305.2009.00342.x

[23] Bernard, K.W., Graitcer, P.L., van der Vlugt, T., Moran, J.S. and Pulley, K.M. (1989) Epidemiological Surveillance in Peace Corps Volunteers: A Model for Monitoring Health in Temporary Residents of Developing Countries. International Journal of Epidemiology, 18, 220-226. https://doi.org/10.1093/ije/18.1.220

[24] Flynn, J., Slovic, P. and Mertz, C.K. (1994) Gender, Race, and Perception of Environmental Health Risks. Risk Analysis, 14, 1101-1108. https://doi.org/10.1111/j.1539-6924.1994.tb00082.x

[25] Centers for Disease Control and Prevention (2020) CDC: Travelers' Health Chapter 4 Travel-Related Infectious Disease Malaria. https://wwwnc.cdc.gov/travel/yellowbook/2020/travel-related-infectious-diseases/m $\underline{\text { alaria }}$ 